https://www.amerabra.org; https://fspu.uitm.edu.my/cebs; https://www.emasemasresources.com/ $9^{\text {th }}$ Asian Conference on Environment-Behaviour Studies Perdana Kota Bharu, Kelantan, Malaysia, 28-29 Jul 2021

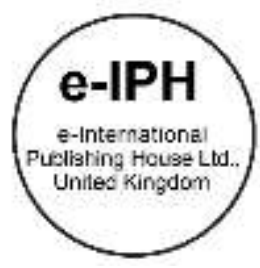

\title{
Pathway Network Design as Natural Surveillance Strategy of Safe Green Roof Environment for Public
}

\author{
Azlan Ariff Ali Ariff ${ }^{1}$, Emma Marinie Ahmad Zawawi ${ }^{1}$, Julitta Yunus ${ }^{1}$, Rodger Edwards ${ }^{2}$ \\ ${ }^{1}$ Centre of Studies for Postgraduates, Faculty of Architecture, Planning, and Surveying, UiTM Shah Alam, Shah Alam, 40450, Malaysia \\ ${ }^{2}$ Department of Mechanical, Aerospace \& Civil Engineering, The University of Manchester, Manchester, United Kingdom
}

azlanariff@uitm.edu.my:,emmarinie@yahoo.com, julitta@uitm.edu.my, rodger.edwards@manchester.ac.uk

Tel : +60192552151

\begin{abstract}
Natural surveillance strategy in public areas can be established with high crowd engagement. Consideration of the type of pathway layout of the green roof would contribute to the rate of public engagement, thus creating a safe environment for people to use the facility. Application of Space Syntax allows the analysis in determining pathway design layout with the highest rate of traffic engagement. Comparing a similar number of nodes and axial lines shows that axial line with more intersecting points creates more possibility of human interaction, higher crowd engagement thus functioning as natural surveillance in green roof setting.
\end{abstract}

Keywords: green roof; natural surveillance; space syntax; building simulation

eISSN: 2398-4287C 2021. The Authors. Published for AMER ABRA cE-Bs by e-International Publishing House, Ltd., UK. This is an open access article under the CC BYNCND license (http://creativecommons. org/licenses/by-nc-nd/4.0/). Peer-review under responsibility of AMER (Association of Malaysian Environment-Behaviour Researchers), ABRA (Association of Behavioural Researchers on Asians/Africans/Arabians) and cE-Bs (Centre for Environment-Behaviour Studies), Faculty of Architecture, Planning \& Surveying, Universiti Teknologi MARA, Malaysia.

DOI: https://doi.org/10.21834/ebpj.v6i17.2803

\subsection{Introduction}

Located on a rooftop, the public tends to miss out on the presence of a green roof. The absence of clear public navigation towards the green roof is primarily caused by the ineffective route and pathway design that leads to the green roof. As a result, green roofs that are located away from public view and paths decrease public reachability, where the public is less expected of the location, exposing the green roof to the possibility of turning into a crime-prone area that is not fit for public use.

Like the rest of the public realm, green roofs with less public engagement and no specific activities that take place give out a sense of unwelcoming. Without working surveillance, the rate of crime surrounding the green roof would increase (Batuman \& Erkip, 2019). These areas are also perceived to be threatening with dangerous corners and no perceived escape route towards the dead end. This type of public area benefits criminal and put the general public into danger of becoming the victim (Kenny, 2020). In contrast to the proportionate relationship between high accessibility and crime issue, several notable building in Singapore such as Marina Barrage has proven that green roof intended for public use could generate a large number of crowds where visitors reported of a safe environment for outdoor recreational purpose. This public perception of a safe environment is a successful implementation of natural

surveillance by the seamless connection from the ground-level pedestrian pathway that welcomes the public onto the green roof. Sharing the same climate and relatively similar demography, such a move initiates the need of understanding a huge viable potential that can improve public accessibility and safety of Malaysian green roofs.

eISSN: 2398-4287C 2021. The Authors. Published for AMER ABRA cE-Bs by e-International Publishing House, Ltd., UK. This is an open access article under the CC BYNCND license (http://creativecommons.org/licenses/by-nc-nd/4.0/). Peer-review under responsibility of AMER (Association of Malaysian Environment-Behaviour Researchers), ABRA (Association of Behavioural Researchers on Asians/Africans/Arabians) and cE-Bs (Centre for Environment-Behaviour Studies), Faculty of Architecture, Planning \& Surveying, Universiti Teknologi MARA, Malaysia.

DOI: https://doi.org/10.21834/ebpj.v6i17.2803 


\subsection{Research Question}

How does the number of intersection nodes in a pathway layout design affect the traffic concentration, and which pathway design has the highest traffic engagement in contribution towards natural surveillance strategy of green roof as public space?

\subsection{Research Aim and Objectives}

This research aims to investigate the relationship between the design layout of green roof pathways with high traffic intensity in improving safety and surveillance aspects as part of the criteria of highly accessible green roofs for the public. The research aim is in line with elaborations of the following objectives; to identify which green roof pathway design layout with the most intersection nodes and to determine which green roof design layout has the highest traffic density. The combination of aim and objective becomes the basis in formulating a guideline in designing a safe green roof environment for the public based on the benefits of high traffic engagement. The scope of the study includes spatial analysis by conducting simulation on different typologies of green roof pathway layout in Malaysia and how each layout configuration contributes positively towards public accessibility which is indicated by high traffic intensity.

\subsection{Literature Review}

\subsection{Green Roof as Public Space}

The idea of turning green roof as public space is widely accepted globally as urban development continue to threaten green space for recreational use in city areas. More recent developments such as office buildings and residential apartments incorporate green roofs as communal spaces that include shared facilities and amenities (Ismail et al., 2018). However, given the location few floors above ground level and hidden from street-level view affecting public visibility on the green roof and reduce public accessibility. Besides that, the green roofs which restrict public use show less consideration on pathway design with no clear indication of the activities (Yuliani and Setyowati, 2020). This causes less public appreciation towards the benefit of the green roof facilities. This is evident in green roof buildings in Malaysian cities, as shown in Table 1 below, where the layout of the green roof pathway reflects public accessibility onto the green roof.

Table 1. Types of pathway layout with local green roof examples

\begin{tabular}{|c|c|c|c|c|c|c|c|}
\hline Layout & Grid & & Perimeter & Radial & Centralised & Linear & Diagonal \\
\hline $\begin{array}{l}\text { Examples of } \\
\text { Green Roof }\end{array}$ & $\begin{array}{l}\text { JST } \\
\text { Plant }\end{array}$ & $\mathrm{N}-$ & $\begin{array}{l}\text { Heriot-Watt } \\
\text { University }\end{array}$ & $\begin{array}{c}\text { Putrajaya International } \\
\text { Convention Center (PICC) }\end{array}$ & The Arc & $\begin{array}{l}\text { Ibu } \\
\text { PKNS }\end{array}$ & $\begin{array}{l}\text { Stratosphere @ } \\
\text { The Roof }\end{array}$ \\
\hline Location & $\begin{array}{l}\text { Johor } \\
\text { Bahru }\end{array}$ & & Putrajaya & Putrajaya & $\begin{array}{r}\text { Putra } \\
\text { Heights }\end{array}$ & Shah Alam & Bandar Utama \\
\hline $\begin{array}{l}\text { Public } \\
\text { Access }\end{array}$ & No & & Special Occasion & No & Yes & Restricted & Yes \\
\hline
\end{tabular}

To allow green roofs as a functional public space, it is essential to put public safety as the main priority when the green roof is accessible for the public. Part of ensuring public safety is establishing working surveillance to ensure no one is vulnerable to crime, especially women, children, and senior citizens.

\subsection{Natural Surveillance in Public Space}

Places with high pedestrian traffic give a perception of security (Nilsson, 2019) where help is all around whenever a crime occurs, as opposed to places less travelled by the public where surveillance watch is needed. However, deliberate placement of security teams can give the public perception of an unsafe environment, thus creating a sense of discomfort of being watched over that induces a sense of privacy invasion which eventually deter public engagement. Alternatively, adopting natural surveillance, such as streetlights, clear views, and strategic entrance points invoke a sense of safety in the environment (Mohit and Elsawahli, 2017). This strategy is formally known as natural surveillance, where theoretically high public engagement provides indirect monitoring for crime watch (Othman, Yusoff \& Salleh, 2019) and is part of defensible space strategy in Crime Prevention through Environmental Design (CPTED). This strategy has proven to be effective in The Bridges Centre, Sunderland where the natural surveillance works by high visibility along the wide, open linear street and throughout the street of Clarence Mew, Hackney which adopts natural surveillance with open visibility from multiple points. In Malaysia, the application of the natural surveillance principle works well in Bulatan Aman Jaya, Ipoh, as shown in Figure 1 where the location of public space at the centre of busy roundabout creates a pivotal focused view where a wide array of recreational activities takes place eliminates the stereotype of associating night time with danger behind the dark.

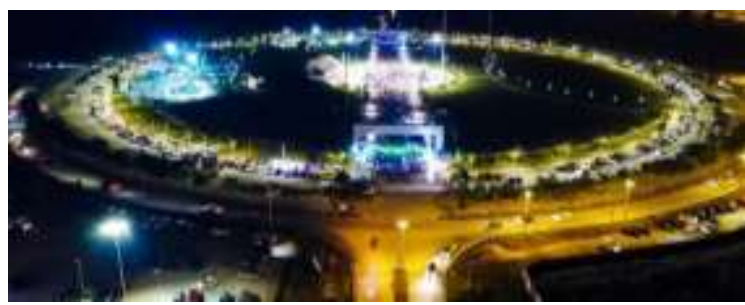

Fig. 1: Aerial view of Bulatan Amanjaya in Ipoh, Perak (Source: Google Maps) 


\subsection{Application of Pathway Design in Natural Surveillance Strategy of Green Roof}

Pedestrian pathway design should prioritise user's experience such as safety, comfortable and continuous (Nasution and Zahrah, 2017). Pathway design with shorter distances increases public mobility where they can walk with ease, relax, and safely (Omar et al., 2016). Unlike ground-level public spaces, the accessibility of green roofs is primarily determined by public mobility criteria and the consideration on pedestrian grade system come second due to less possibility of having overlapping pedestrian circulations with vehicular access. As the green roof pathway is an extension of the building's circulation, the same consideration of public mobility should comply to ensure public inclusivity for a highly accessible green roof as a public space that provides seamless continuity when connected to main pedestrian circulation. This is where the design pathway plays an important role to allow more public engagement. Public engagement depends on the connectivity of the path, where a path with more intersections creates more traffic concentration (Nordin and Nakamura, 2019). A high concentration of traffic establishes active natural surveillance.

\subsection{Application of Space Syntax in Natural Surveillance Strategy of Green Roof}

While it is known that pathways in general functions to provide accessibility and facilitate human movement from one point to another point, different pathway designs are different in terms of distance and rate of public engagement as a result of intersecting points (Omar et al., 2016). These intersecting points, better known as nodes in urban planning design, induce a focused concentration of traffic, which helps to create a safe environment (Abd Rahman, Thani, and Roslan, 2017). A selection of theories and strategies for examining the social and cognitive features of an architectural or urban plan in mathematical and computational terms is known as Space Syntax. Space Syntax is a popular tool in assessing traffic volume pedestrians in urban studies, which involves spatial analysis of wider scale networks. A network in spatial interaction works with the identification of a series of intersecting points known as nodes and arcs in between segments that are measured by some assumed distance measurement. Nodes or arcs in the network are not counted as unique definitions in any specific means as spatial interaction works in a neutral setting (Batty, 2017). Sets of segments with respective attributes generate the sequences of links that define streets. Space syntax recognizes defined streets by the existence (1) or not (0) of a node in the original network that determines the connectivity of the streets. This definition is applicable in assessing the connectivity of pathways of a green roof that take into consideration the placement of nodes with high traffic concentration to establish natural surveillance on the green roof.

\subsection{Methodology}

Green roof layout is selected based on typical green roof pathway design layout which is derived from local building samples as shown in Table 1 and controlled at consistent acreage for each variant. Variations of pathway design are endless, where the combination between two or more types of primary pathway layout results in the formation of thousands of possible layouts. Hence, the study focuses on the primary pathway layout and their properties of engaging human traffic. The selection of types of primary pathway layout for this analysis is a close reference to local green roof examples documented in Table 1 of the Literature Review chapter to reflect the actual study on the existing green roof scenario. The application of Space Syntax in this study helps to determine which layout has the highest traffic engagement. Primal graphs translate the samples in a comprehensive illustration where nodes represent intersecting points while edges define pathways. The conversion of analytic data via simulation into a visual presentation is comprehensive, where different intensity translates into colouration intensity with means of colour-coded maps. Colour-coded maps range from red to indicate high traffic concentration to blue which suggests low traffic density. This presentation provides a more straightforward overview without analysing raw data in the form of elaborated tables and calculations. Detailed data computation is also readily available for in-depth spatial analysis as the computed inputs are generated in the background along with the visual graph analysis. This method of Spatial Design Network Analysis (sDNA) is relevant to the scale of a green roof and applicable to the two-dimensional spatial analysis of this study.

Figure 2, Figure 3 and Figure 4 show the conversion of pathway design layout from base pathway layout to axial line to graph analysis as the result of Space Syntax simulation. Generation of axial lines follow the pattern of the pathway layout but is limited to two conditions that allow simulation graph to take place where each axial line must be in a continuous straight line and intersect at the ends to generate a connection between two or more axial lines aligned in different direction and orientation. The axial lines are analysed using Depthmax Space Syntax, thus showing the colour-coded line mapping that provides information on traffic intensity in a

form of graph analysis (Figure 4). Graph analysis which generated from Space Syntax simulation that translated into colour-coded maps showing ranges of colouration from red to indicate high traffic concentration to blue which suggests low traffic density
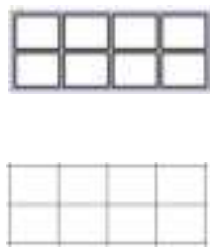
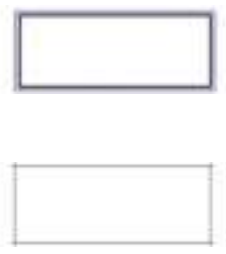

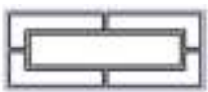

Fig. 2: Pathway layout
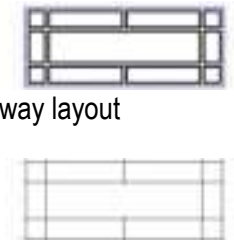

Fig. 3: Axial line derived from pathway layout

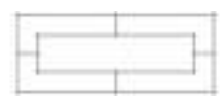

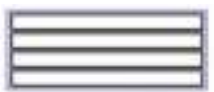
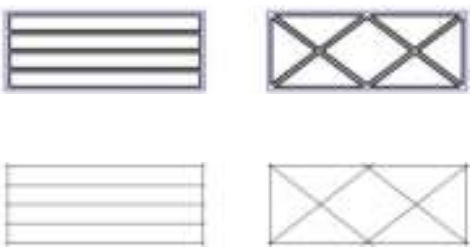


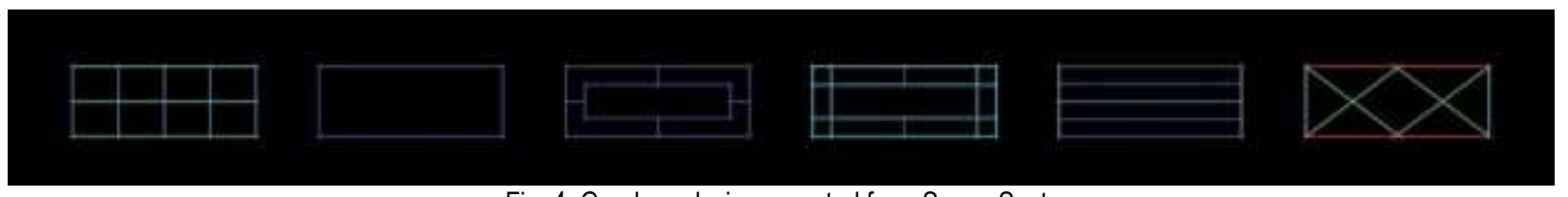

Fig. 4: Graph analysis generated from Space Syntax

Table 2. Types of pathway layout with respective axial lines and nodes count

\begin{tabular}{|c|c|c|c|c|c|c|}
\hline $\begin{array}{l}\text { La } \\
\text { yout }\end{array}$ & rid $G$ & $\begin{array}{l}\text { Peri } \\
\text { meter }\end{array}$ & $\begin{array}{c}\text { adial }^{\mathrm{R}} \\
\end{array}$ & $\begin{array}{l}\text { Centr } \\
\text { alised }\end{array}$ & $\begin{array}{l}\text { Li } \\
\text { near }\end{array}$ & $\begin{array}{c}\text { Dia } \\
\text { gonal }\end{array}$ \\
\hline $\begin{array}{l}\text { Ax } \\
\text { ial } \\
\text { Lines }\end{array}$ & 8 & 4 & $\begin{array}{ll} & 1 \\
2 & \end{array}$ & 10 & 7 & 8 \\
\hline $\begin{array}{l}\quad \mathrm{N} \\
\text { odes } \\
\text { Count }\end{array}$ & $5^{1}$ & 4 & $5^{1}$ & 20 & $\begin{array}{ll} & 1 \\
0 & \end{array}$ & 10 \\
\hline
\end{tabular}

\subsection{Findings}

Different pathway layout consists of a different number of axial lines. Configuration of axial lines according to the pattern of pathway layout influences the points of intersection in the pathway design, shown by the nodes count. As shown in Table 2, the radial layout consists of the most number of axial lines, while the centralised layout has the highest nodes count. Figure 5 shows the placement of each axial line, while Figure 6 indicates the location of nodes in the respective layout. Despite having the most number of axial lines, the colouration intensity shown in the radial layout is comparatively similar to the perimeter layout, which has only four axial lines. Linear pathway layout shows equal colour intensity with perimeter and radial with exception to the higher concentration at the middlemost line and the lines connecting both ends. The centralised layout shows higher colour intensity compared to the grid layout, and the diagonal pathway design shows the overall highest traffic concentration, as evident in red-coded axial lines. As an overview, the number of axial lines and the number of nodes is not the dominant factors in determining the rate of traffic engagement. The finding extends to another aspect of discussion which observes the impact of nodes configuration and overlapping axial lines on public engagements.

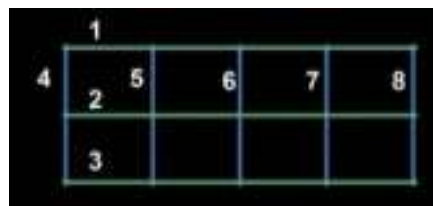

(a)

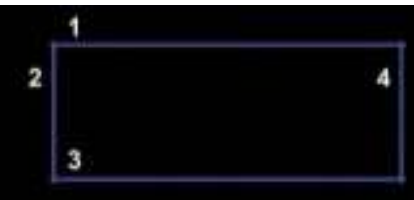

(b)

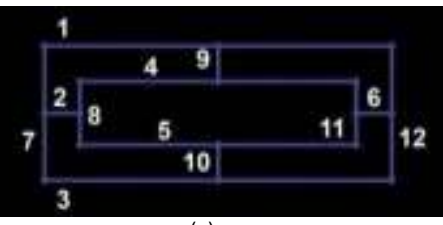

(c)

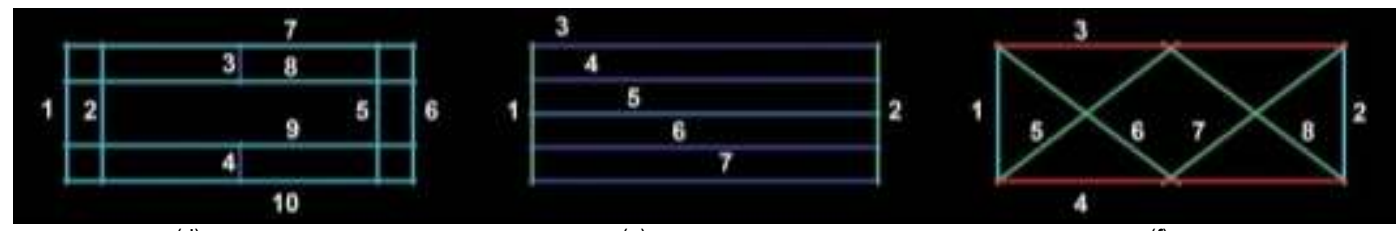

(d)

(e)

Fig. 5: Axial lines configuration for each pathway layout:

(a) Grid layout; (b) Perimeter layout; (c) Radial layout; (d) Centralised layout; (e) Linear layout; (f) Diagonal layout

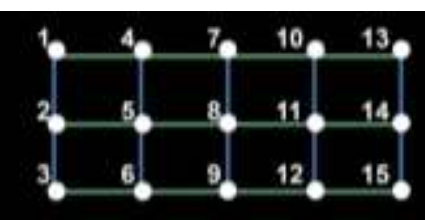

(a)

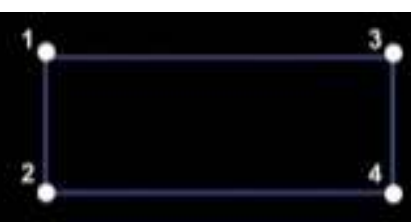

(b)

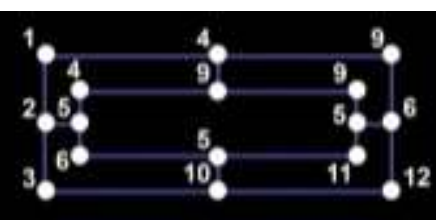

(c)

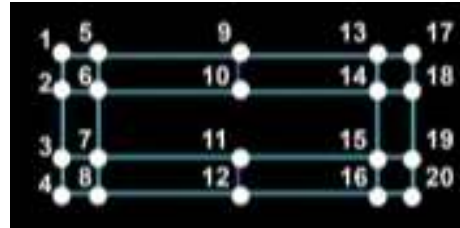

(d)

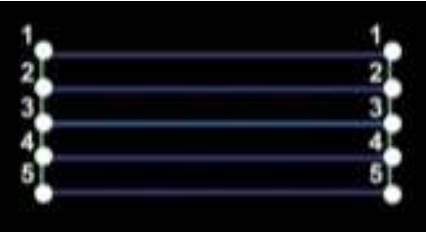

(e)

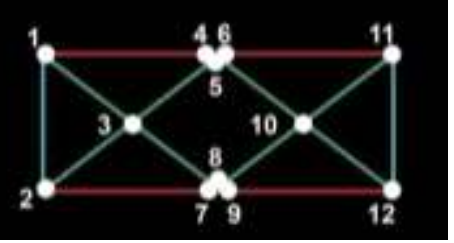

(f)

Fig. 6: Configurations of nodes for each pathway layout :

(a) Grid layout; (b) Perimeter layout; (c) Radial layout; (d) Centralised layout; (e) Linear layout; (f) Diagonal layout 
The colour code of the axial line for the perimeter layout shows consistent blue colouration, which suggests an even distribution of low traffic concentration for each axial line. The colouration of radial layout and perimeter layout shows relatively similar intensity which indicates that more axial lines in a pathway design do not contribute to a significant impact in improving crowd engagement. However, comparing the longer axial line with more nodes with the shorter axial line with fewer nodes count, the latter shows higher colouration of crowd density. This suggests that the length of the route has a substantial influence on traffic concentration, supporting the theory that pathway design with shorter distances increases public mobility (Omar et al., 2016). In linear pathway layout, the number of nodes varies by either two or five, where shorter axial lines that connect the perpendicular lines show higher colour intensity than longer axial lines with nodes located at both ends. This further supports that shorter lines with more nodes contribute positively towards high traffic concentration. Compared to linear pathway design, the most extended axial lines in diagonal layout shows the highest traffic intensity compared to other lines. However, both linear pathway design and diagonal pathway design shares the same strategy that allows traffic concentration; closely located nodes.

Table 3. Grid layout nodes count per axial line

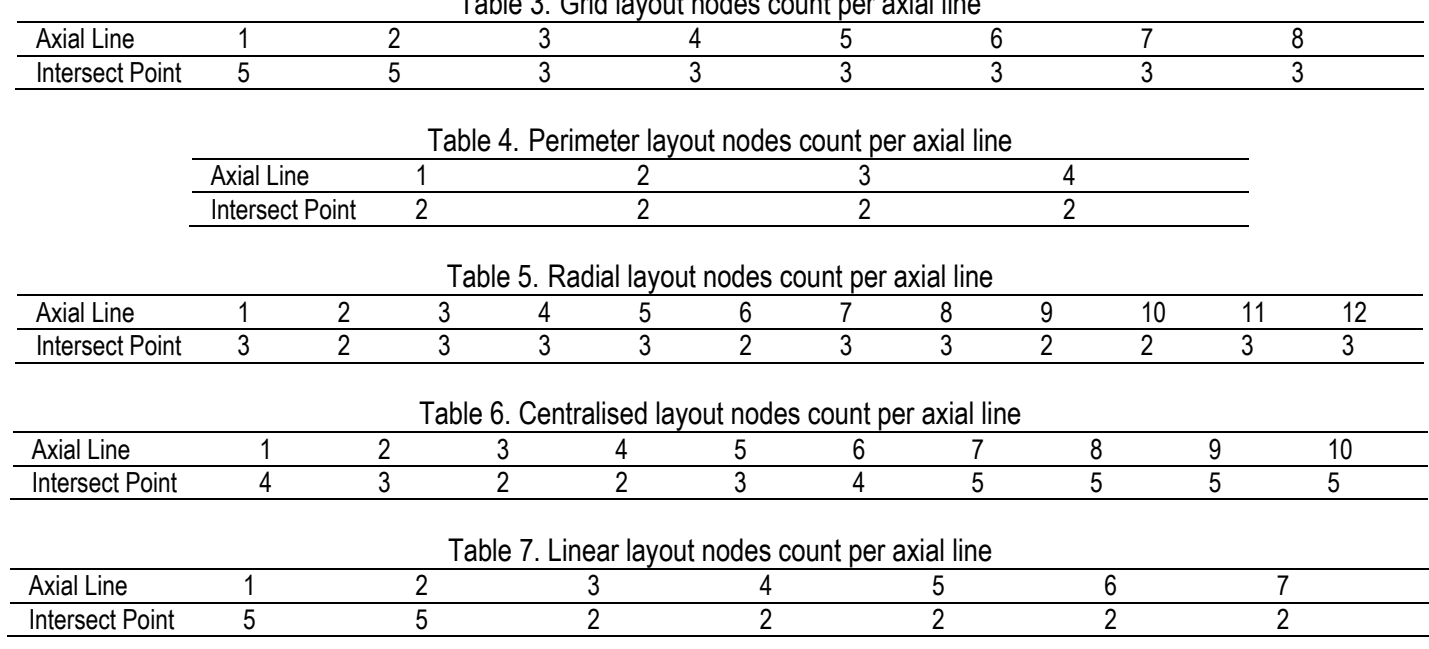

Table 8. Diagonal layout nodes count per axial line

\begin{tabular}{lllllllll}
\hline Axial Line & 1 & 2 & 3 & 4 & 5 & 6 & 7 & 8 \\
\hline Intersect Point & 4 & 4 & 6 & 6 & 5 & 5 & 5 & 5 \\
\hline
\end{tabular}

\subsection{Discussion}

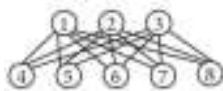

(a)

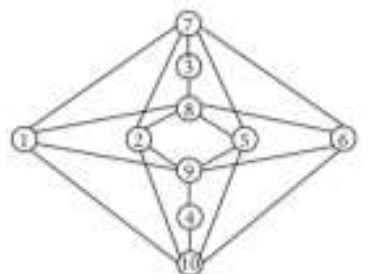

(d)

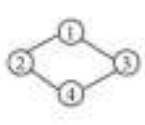

(b)

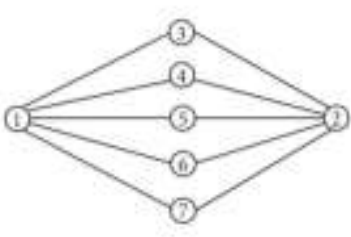

(e)

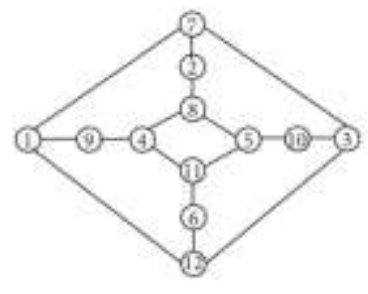

(c)

Fig. 7: Primal graph for each pathway layout (a) Grid layout; (b) Perimeter layout; (c) Radial layout; (d) Centralised layout; (e) Linear layout; (f) Diagonal layout

The illustration of the primal graph for each pathway design as shown in Figure 7 above provides a better understanding of the relationship between nodes, axial lines, and intersecting points. Numbered points are the translation of axial lines where one point could become the meeting point of several other points, or one point could connect multiple points. In the Grid layout, only three axial lines intersect with five different lines, and the remaining five axial lines connect to three lines consistently. The perimeter layout in Figure 7(b) shows a constant 
meeting point of two for each axial line. As for the radial layout shown in Figure 7(c), the number of intersection points for the axial lines ranges between two to three, where points with three intersection points are the axial lines connecting the inner perimeter with the outer perimeter, adhering to the nature of the radial pattern. In the centralised layout shown in Figure 7(d), there is a broader range of nodes count per axial line between two to five. This is due to axial lines at the perimeter intersect with internal axial lines that make up the centralised layout pattern. Lastly, the diagonal pathway layout in Figure 7(f) generates more intersection points of four to six per axial line. With the diagonal pathway design, more lines would overlap with each other, creating more nodes located close to each other, as shown in Figure 6(f) that answers the chances of making more crowd engagement. Concerning natural surveillance, such a layout that garners high traffic concentration within a focused area establishes a safe environment.

\subsection{Conclusion \& Recommendations}

Pathway layout design plays a vital role in ensuring the public's safety on a green roof to function as a highly accessible public realm. Higher public accessibility introduces more traffic engagement that establishes natural surveillance that creates a safe environment onto the green roof for all to enjoy. Through graph analysis generated by Space Syntax, the diagonal pathway design shows the highest traffic intensity as evident in both colour-coded graph analysis which is indicated by red colouration and primal graph with a network of overlapping lines suggesting higher chances of crowd concentration. The nature of the diagonal layout satisfies the critical aspects that garner high traffic concentration, namely short distance, more intersecting points, and closeness of nodes that increase the chances of public engagement. This supports the statement by Nordin and Nakamura (2019), thus validates the soundness of Space Syntax as a recommended tool in assessing human traffic behaviour in spatial analysis. Space Syntax as a methodology in determining human interaction within a space helps to simplify the overall computed analysis thus, it suits the nature of this study to assess the pathway design layout that has comparative high crowd engagement. Space Syntax eliminates the need of understanding elaborated and complicated analytics into graphical translation by adopting colour intensity as a form of visual communication. This study could extend to the assessment of green roof layout using convex space, integration of pedestrian grade system onto the green roof for different types of accessibility and different variations of layout design which can be formed with a combination of two or more layouts.

\section{Acknowledgements}

Funding towards the presentation and publication of this paper is made possible by REI grant, 600-IRMI/REI 5/3 (008/2018). The authors fully acknowledged Universiti Teknologi MARA (UiTM) for the approved fund which makes this vital research viable and effective.

\section{Paper Contribution to Related Field of Study}

This paper contributes to providing an extension of study in the existing scarce discourse on the social aspect of the green roof by bridging the relationship between spatial analysis and human behaviour towards developing a natural surveillance strategy for a highly accessible green roof. The application of natural surveillance on green roofs has a huge potential to be part of future green roof guidelines in terms of safety measures among public. This paper also establishes the use of Space Syntax as a relevant instrument in the micro-scale of green roof study which is usually more popular in the macro-scale context of urban studies.

\section{References}

Ab Rahman, Z., Thani, S. K. S. O., \& Roslan, R. (2017). Demystifying the Roles of Streets towards Improving Urban Quality of Life. Environment-Behaviour Proceedings Journal, 2(5), 427-437.

Batty, M. (2017). Space Syntax and Spatial Interaction: Comparisons, Integrations, Applications.

Batuman, B., \& Erkip, F. (2019). "Night Hawks" Watching Over the City: Redeployment of Night Watchmen and the Politics of Public Space in Turkey. Space and Culture.

Ismail, W. Z. W., Abdullah, M. N., Hashim, H., \& Rani, W. S. W. (2018). An overview of green roof development in Malaysia and a way forward. In AIP Conference Proceedings (Vol. 2016, No. 1, p. 020058). AlP Publishing LLC.

Kenny, J. F. (2020). Lurking in the Shadows: Stranger Danger and Target Selection. In Hiding in Plain Sight (pp. 45-58). Palgrave Macmillan, Cham.

Mohit, M. A., \& Elsawahli, H. M. H. (2017). Crime and Housing in Kuala Lumpur: Taman Melati terrace housing. Asian Journal of Environment-Behaviour Studies, 2(2), 5363.

Nasution, A. D., \& Zahrah, W. (2017). Exploring Ideas in Formulating Urban Design Guidelines for Public Open Space in Sumatra Utara, Indonesia. Environment-Behaviour Proceedings Journal, 2(5), 439-447.

Nilsson, J. (2019). A Public Space Analysis and Design Proposal for Täby Torg: Understanding Public Life and Designing for It.

Nordin, N., \& Nakamura, H. (2019). The Relation between Objective and Perceived Physical Characteristics of a Neighbourhood Environment for Older People, EnvironmentBehaviour Proceedings Journal, 4(11), 63-71.

Omar, D., Omar, K. A., Othman, S., \& Yusoff, Z. M. (2016). Walkability design for urban public housing park. Environment-Behaviour Proceedings Journal, 1(3), 311-317. 
Othman, F., Yusoff, Z. M., \& Salleh (2019). Identifying Risky Space in Neighbourhood: an Analysis of The Criminogenic Spatio-temporal and Visibility on Layout Design Environment-Behaviour Proceedings Journal, 4(12), 249-257.

Yuliani, S., Hardiman, G., \& Setyowati, E. (2020). Green roof: The role of community in the substitution of green space towards sustainable development. Sustainability, 12(4), 1429. 